Tavistock and Portman NHS Foundation Trust, London NW3 5BA, UK

raka.maitra@gmail.com Cite this as: BMJ 2020;370:m3106 http://dx.doi.org/10.1136/bmj.m3106 Published: 07 August 2020

MAKING THE MOST OF SHIELDING

\title{
Making the most of shielding: covid-19 is exposing the unpaid carers in NHS workforce
}

\section{Raka Maitra specialty trainee year 4, child and adolescent psychiatry}

Perhaps identifying those who are clinically vulnerable has been one of the kindest endeavours this year. ${ }^{1}$ Letters of support and guidance from the NHS and the NHS Volunteer Responder Scheme, and guidance from NHS Employers for working from home $^{2}$ and supporting staff with childcare responsibilities, ${ }^{3}$ are compassionate initiatives that recognise the importance of facilitating work and embracing personal circumstances.

A 2019 Carers UK report shows that one in seven people in the UK are juggling work with unpaid caring responsibilities, ${ }^{4}$ although specific data about the number of unpaid carers or the number of unpaid carers shielding are not available for the NHS workforce.

Those who are shielding to take care of a vulnerable child or family member have coined their own term-“shielding by proxy.” Doctors shielding and shielding by proxy have contributed to non-clinical work ${ }^{5}$ and many have continued to do significant clinical work remotely without reducing their hours. ${ }^{1}$ Although there may be a determination to continue to work and train despite challenging circumstances, guilt may also contribute to the vulnerability of those shielding and especially those shielding by proxy.

As we prepare to return to normality it is imperative that NHS Employers, NHS trusts, and health education bodies consider whether return to business as usual blinds them to the ongoing caring responsibilities of this workforce.

Covid-19 has shown us that clinical and non-clinical work, as well as clinical training, can be safely carried out remotely. Perhaps when we recognise unpaid carers in the NHS, the compassion shown to those shielding by proxy will pave the way for a new normal $^{6}$ in healthcare.

Competing interests: None declared.

Full response at: www.bmj.com/content/369/bmj.m2443/rr-0.

Rimmer A. How can I make the most of my time shielding?BMJ 2020;369:m2443. doi: 10.1136/bmj.m2443 pmid: 32571961

2 NHS Employers. 2020. Enabling and supporting staff to work from home. www.nhsemployers.org/covid19/health-safety-and-wellbeing/enablingand-supporting-staff-to-work-from-home

3 NHS Employers. 2020. Supporting staff with childcare responsibilities. www.nhsemployers.org/covid19/health-safety-and-wellbeing/supporting staff-with-childcare-responsibilities

4 Carers UK. 2019. Juggling work and unpaid care report. www.carersuk.org/images/News_and_campaigns/Juggling_work_and_unpaid_care_report_final_0119_WEB.pdf

5 Miller S. Re: How can I make the most of my time shielding? [electronic response to Rimmer A. How can I make the most of my time shielding?]. BMJ 2020. www.bmj.com/content/369/bmj.m2443/rr.
6 Maitra R. A "new normal" after covid-19 for NHS healthcare workers who are also carers?BM/2020;370:m2640. doi: 10.1136/bmj.m2640 pmid: 32620581 